\title{
LASER SURFACE MELTING OF A Cr-Ni-Mo CAST IRON: A MICROSTRUCTURAL STUDY
}

\author{
R. VILAR, J.S. FIGUEIRA* and M.O. BAPTISTA**
}

Instituto Superior Técnico and CEMUL, Av. Rovisco Pais, P-1096 Lisboa, Portugal

*Instituto Tecnologico para a Europa Comunitaria, Av. Rovisco Pais, P-1096 Lisboa, Portugal

**Instituto Superior de Engenharia de Lisboa, R. Conselheiro Emidio Navarro, P-1900 Lisboa, Portugal

\begin{abstract}
Samples of a low alloy Cr-Ni-Mo mottled cast iron were melted using $\mathrm{CW} \mathrm{CO}^{2}$ laser radiation. The laser treated layer presents severe defects, mainly cracks and pores. The amount of defects depends on the laser treatment technique, on the exact choice of operating parameters, as well as on the cast iron elaboration procedure. The best results were obtained using moderate power density, long interaction times, a moderate overlap between consecutive tracks and preheating the samples. The size of the graphite lamellae and the impurity content must be restricted to reduce the density of pores. The microstructure of the resolidified material depends also on the laser treating parameters. When the scanning speed is low, the solidification structure contains primary austenite dendrites in a ledeburitic matrix. During cooling, austenite transforms partially into martensite. An increase in the scanning speed leads to a decrease in the fraction of ledeburite and to a increase in the fraction of retained austenite. When the scanning speed exceeds a limit which depends on the power density, normal lamellar ledeburite disappears and a solidification structure consisting of long austenite dendrites with a interdendritic film of cementite forms. No martensite was detected in this case.
\end{abstract}

